\title{
A Course for Life
}

\section{Maimouna Al Alawi}

As a student in the Health Sciences program, I have to take many college-required courses, and one of these was Human Physiology. This course is a combination of anatomy and physiology; it covers the structure and organization of the body, metabolic processes and different functions in the body. It covers the body systems such as the nervous system and the cardiovascular system, and diseases such as autoimmune diseases; it also shows us how technology helps in scanning and testing procedures. Dr Cindy was the instructor of this course; it was one of the most enjoyable times that I have had, and I will never forget it. I think even if it was not required, I would take it because the information I gained is necessary and every person should learn it because it is essential for a lifetime.

Learning styles vary from person to person. For example, my friend always likes to take notes, and depends completely on these; if the teacher uses a lot of powerpoint presentations, another student might like to print these and study from them. I am different again: I like studying from the source of the information. For instance, I prefer studying from the book rather than from the teacher's presentations. This does not mean that I do not read the powerpoints, but I always read and seek for details from the book, even if the exam does not require us to know the details.

Understanding the concept or the topic is very important. In this course, you need to get a deep understanding of the different processes in the body, such as how blood is sent by the heart to the rest of the body, or the way the blood gets the oxygen. By understanding these processes and the others, we will be able to tell others about it, and explain it when needed in exams or presentations.

I remember one topic about how signaling of the brain is transferring to the organs and so forth. I did not understand that lesson because I was absent and the topic is complicated for a student to understand at first. I depended on my own understanding to get the point, reading the section in the book and going through her presentation as well; but still it was not so clear in my mind. I ignored it for a while and then forgot about it; during the course, we had two tests on this topic, as well as other topics as Dr Cindy planned, and I did not answer it well, because I did not understand it very well. Finally, in our last revision at the end of the semester, I did understand it when she explained it in two sentences, summarizing the concept of how the signals travel from the brain centre to the organ so that it contracts (takes action). The teacher summarized it in a simple drawing with arrows of the signals' pathway and bullet points showing the steps. It was so easy to follow the points and get the whole idea. Now, I still remember it; even if you asked me now, I could answer. This shows how important understanding is in the studying period, and in all steps in life.

Reviewing is another way that I study. I do my review from the presentation, from any notes I wrote, and from the book as the main review tool. I like the book because it has all the information needed and you can find terms, definitions and explanations. I also like it because in the book it is presented in a very clear and organized way, with the main topic, then the sub topics, then the details; this makes it easy to follow up. 
For example, they print all the headings in a large, bold font, and the details in a smaller or different font or color. Another helpful thing in our book was the images: the photos, graphs and diagrams are well drawn in the book, helping us to understand the message in the text.

In the powerpoint presentation not everything is written but only the main points, so you have to go back to the book anyway to make sure you know the idea and be able to answer any question related to this idea. The physiology book is an excellent book to use, even for students who don't take this course. The language of the book is accessible, the explanations are easy to follow, the terms are well defined and the images are very clear and colored. As I am a slow learning person, the book allows me to keep reviewing the words, points and graphs until I memorize them. The way I do this is by repeating the words and sentences verbally. From my experience I found that the information sticks in my mind more with books than with powerpoint slides. For example, in the topic on the muscular system, the book gives a lot of detail that is not required for the course, but is nice to know. In the book they talk about the types of muscles, their shapes, their names and formation. In the lessons we did not go into much detail on the names and functions; we reviewed it in a lab session but it was not required for the exam. Using the book in this case gives us the idea of their different functions and relates the functions to the type of muscle needed and the bones involved with the muscle.

A further learning strategy, most important for me, is linking ideas. I am very bad at memorizing, so I planned to solve this problem by using a method to keep me remembering things as well as understanding. I tried to link ideas together when studying, and I found it saved time and effort. Linking ideas was what led past scientists to understand and create things such as gravity or electricity. In my case, for example, I had a hard time memorizing the blood circulation through the heart; so what I did was to think about it in this way: thin means less, so thin-walled chambers of the heart have less work and less effort and they are responsible for receiving blood from arteries. On the other hand, thick means more: thick-walled chambers can pump the blood to the lungs to get oxygen, and to the whole body.

Handling real things is the best way of learning, especially for kids and science courses. Some teachers might think that university students are adults, not kids, and so we don't need to handle real things in order to understand; but even professors sometimes play with things to get an idea. How could inventions have been created without handling real things? How could scientists know the movement of the heart without handling a heart and observing its contraction? Maybe some courses like social studies don't need objects, but science definitely needs this. In education you can't say "this is a kid and this is an adult", because education puts the more knowledgeable person at the top and the less educated person at the bottom, whether he/she is an adult or a child. This is why education is such a valuable concept, that societies are judged by.

I agree that the teacher must give the students a chance to think critically and try depending on themselves, but I don't agree with the teacher who leaves the students to depend totally on themselves without giving them a start - especially in science, because once the student has built their ideas and understood anything in the wrong way, it takes a lot of time and effort to change the first wrong idea. In this course, we used to handle things that are available in the biology lab. For example, understanding the location and names of the organs and their functions became easy when I played with the anatomical model, taking parts out and putting them in their right location. Try looking at the bones in your hand, touching it and thinking about how different bones vary with shape, size, structure and location. I still remember 
every detail of that lab session and the whole discussion, even the conversations I had with my friends.

Dr Cindy knew how to teach her students and help them understand, so we were able to do the tests and to tell others about the information we gained. First I will talk about classes. In every class, she reviewed the most important points in the previous lesson, so we connected the current one with the last one. She always simplified the ideas, especially processes, and discussed the main parts. Then when she had made sure we understood those, she went through the details one by one so we could get the points.

As I said previously, linking ideas is essential for learning, and she took this into account. When she was teaching, she always linked the ideas together to make sense of why or how. As the human body is very complex and the organs interact with each other, being aware of these linkages makes it easy for you to think of why things might occur or why this organ is located in a certain place and not another.

In the lab sessions the lessons were more interesting. For example, we did some cross-sections on rats. As students and girls doing it for the first time, I felt a kind of fear, and at the same time I wanted to do it. The first session was cutting the head and removing the brain without destroying it. It was difficult because you have to get out the skull which is very close to the brain, and you don't know how deep your scalpel has gone. It was challenging, and she did it in front of us first, then we followed her so the directions were clear. After the first session, we were familiar with using these sharp instruments.

Sometimes in the lab when the materials were not available, we used websites to learn. For example there are anatomy websites where you can rest your mouse pointer on a word, and writing appears, like when you point the mouse at the icon for a document and it shows you information about this document. In this case, we pointed the mouse at the name of a bone, muscle or organ, and a brief description appeared. Another good website allows you to select a certain bone and drag to its correct location; then the website tells us whether it is correct, and another box on the right of the screen appears with some information - usually the name, type, main functions and location of that bone. For example: the humerus is a long bone located in the upper part of the leg and it is responsible for the body balance while walking, running and standing and to hold the body. This also helps you to learn because in the exam you may not remember reading the word or the paragraph in the powerpoint slide or book, but you will remember moving your hand and doing the matching on the website.

We did some short answer reports, in which we had to say for example which functions relate to which organs. The exams, which students usually fear and complain about in other courses, seemed easy because we were well prepared. I liked her final exam most, because it connected all the material we had covered. Four review lectures before the exam really helped us to understand the whole body. Each lecture reviewed one topic (blood pressure, sugar, energy and calcium), giving an overview of everything we had studied in the course that related to that topic, and making the picture clearer and more comprehensible.

I said previously in my introduction that the information I gained in this course is necessary for every single person and should be passed on to other people, not only health science students. The most important thing is that you learn how our body is organized in a way that we can't imagine. Understanding this organization will make you aware of how precise God is in creating us, so that he did not make one tiny 
mistake! This for us as Muslims is very important. It makes me feel closer to my God, and it gives us a feeling of how important it is to value our body more and to thank God for giving such organs that fit our needs. For example, we have one liver, including many sections, while we have two kidneys. If there was only one kidney, imagine the heavy pressure which would load it - it is so small and couldn't take that. Having two kidneys which are located in an organized way is to keep balance in the inner body and share work between them. The kidney is the key part of the urinary system, so consider if a person has a problem or disease in the kidney and he/she has to have it removed. What could that person do if he/she does not have an alternative kidney functioning? If we think more deeply, why is the liver divided into parts as an organ? The answer to this is because the liver is so important in the digestive tract. If anybody gets a disease in it, physicians can isolate the damaged part, leaving the other parts safe and the liver can function normally! This is amazing.

In addition, learning the human physiology will make you treat your body like a friend, or another person. For instance, sadly some people eat too much at every meal. Knowing about the process of digesting the food in the body and how the process works will make them aware of the importance of taking a rest or break between meals, and even during the meal they should eat slowly, and chew the food in the mouth before digesting it. Actually, the teeth are in the mouth to break the food into pieces so that it becomes easier for the stomach to add the substances needed to react with it; then it travels to the intestine and stays a longer time there for the nutrients to be absorbed into the body. Another example is that some people smoke: this puts the body under so much pressure, and they don't realize what is going on inside them. As I mentioned earlier, the body is a community with various workers. In the case of smoking more than one group is functioning: when you smoke you stop the lungs from getting the adequate amount of oxygen required in the body. Less oxygen means less health because almost everything in the body depends on oxygen. The carbon substances and other dangerous products from the cigarette will be trapped in the lungs and kill the cells. Killing the cells means slowly killing the whole organ, which is the lung. Treating the body as a friend includes giving every part its rights. For the lungs, you give them sufficient oxygen: avoid polluted air as much as possible, so that we don't make it suffer. Another group which is affected by smoking is the immune system, our body's defense. This keeps fighting foreign bodies, which are the dangerous substances inhaled, until we quit smoking. If you understand how hard every organ is working, and how they work, I really believe you will change your mind about how you treat your body.

I have used this information by telling my friends and family about it, and teaching them about the functions and importance of each organ and system in the human body. I also use it to detect sometimes the source of my pain. For example, if I have pain in my leg, I can say it is because the pressure I put on a joint when I walked a long distance without stopping for rest. I use it to teach myself and my family a healthy lifestyle. Before this course I did not care that much about water, but after studying the importance of water in getting oxygen I remind myself always to drink water whenever possible. The brain is our main source of information and thinking, and it is more complicated than a program in a computer. You have to give it a break to rest: don't make it work all the time so that it gets tired and you start creating problems in your brain. Sleep well and gives it its right to have rest. Now when I hear about a disease in a certain organ, I can identify the reasons for that disease or at least how the organ needs to be treated. Of course this is only one course and you still need years more in order to identify diseases and treatments, but I am certain that it opens your eyes to certain things and opens the window for you to treat your body in the way it deserves. 